imperfectly the place of a positive result. Let us see if a positive interpretation is compatible with the facts.

In face of so emphatic a declaration to the contrary, my opinion may seem over bold; yet I feel no hesitation in believing that the inheritance of eye-colour in these mice, so far as the record reaches, was strictly Mendelian. The first cross proves that when in this case an albino (pinkeye) gamete, G, meets a colour-bearing (pink-eye) gamete, $\mathrm{G}^{\prime}$, in fertilisation we must expect the resulting heterozygote, $\mathrm{GG}^{\prime}$, to be coloured in coat, with a dark eye. When these heterozygotes breed inter se, they will form on an average equal numbers of homozygotes, $\mathrm{G} G$ and $\mathrm{G}^{\prime} \mathrm{G}^{\prime}$, and of heterozygotes $\mathrm{GG}^{\prime}$ and $\mathrm{G}^{\prime} \mathrm{G}$. Of these, the homozygotes will all have pink eyes, but while $\mathrm{GG}$ will have a white coat, $G^{\prime} G^{\prime}$ will have some colour in the coat. The heterczygotes, $\mathrm{GG}^{\prime}$ and $\mathrm{G}^{\prime} \mathrm{G}$, will have dark eyes and some colour in their coats.

Treating $\mathrm{GG}^{\prime}$ and $\mathrm{G}^{\prime} \mathrm{G}$ as identical, we thus expect the ratio

$$
\text { I GG: } 1 \mathrm{G}^{\prime} \mathrm{G}^{\prime}: 2 \mathrm{GG}^{\prime} \text {. }
$$

Therefore the most probable distribution of the 66 mice is as follows :-

16.5 pink-eyed albinos: 16.5 pink-eyed with colour in coat: 33 dark-eyed with colour in coat,

and the experiments gave

13 pink-eyed albinos : 17 pink-eyed with colour in coat : 36 dark-eyed, (? all) with colour in coat

Similarly, on crossing the hybrids with albinos, we expect equal numbers of $G G$ and $G G^{\prime}$. Therefore the most probable distribution of the 205 mice so produced is

102.5 pink-eyed albinos : $102^{\circ} 5$ dark-eyed with colour in coat, and the experiment gave

II I pink-eyed albinos:94 dark-eyed with colour in coat.

Experiment agrees well with expectation. In what respect are they discordant?

The case is closely comparable with that found by Miss Saunders in Matthicla (Rep. to Evol. Cttee. of Rov. Soc, I902), when a white hoary form crossed with a white glabrous form gave purple hoary offspring; and with the production by Kölreuter (confirmed by Gärtner, Naudin and Godron) of purple flowered hybrids by the union of two white flowered Daturas, D. ferox and D. laevis. Why in these cases the heterozygotes are atavistic we do not know, but the problem need not be insoluble.

Anyone conversant with Mendelian phenomena can now predict the eye-colour of the future offspring of the various unions with approximate accuracy. Pending further experiments, we cannot predict the particular colours which will appear in the coats, and for various reasons we should perhaps be cautious in declaring that ail the dark-eyed mice must show colour in their coats.

From incidental comparisons of these new facts with the simpler results of von Guaita an inexperienced reader might suppose that the two sets of experiments had been comparable and had given discrepant results. It would have prevented misconception if the author had stated that while the waltzing mice he used were pale fawn and white with pink eyes, von Guaita's were black and white with dark eyes. It is a feature of the Mendelian view of heredity that different specific results may be expected when different specific materials are introduced.

Grantchester, Cambridge, March 11 .

\section{University Education in the United Kingdom and Germany.}

With reference to the admirable article on "The University in the Modern State " which you published in your issue of March 12, may I point out that the figures you give deal only with university education in Germany in arts, pure science, law, medicine, \&c. ; they do not include the very large expenditure on technical education of university rank. Both in that country and in the United States such education is given in technical institutions existing side by

NO. I 742 , VOL. 67] side with universities, but free from ordinary academic control.

Were these figures added, the comparison you make between the sums devoted to higher education in this country and in Germany would be still more striking. For-to take a single case - side by side with the well-endowed University of Berlin, there is the Technical High School at Charlottenburg, which is one of the finest technical institutions in the whole world, liberally supported by the State, and, notwithstanding the jealous protests of the Prussian universities, wisely authorised by the German Emperor to grant degrees in the main branches of technical knowledge.

$$
\text { J. Wertheimer. }
$$

Merchant Venturers' Technical College, Bristol, March 16.

[The series of articles referred to of set purpose deals with universities only.--Ed.]

\section{Hygrometric Determinations.}

DURING the past week I have made some determinations with regard to the humidity of the atmosphere at this place, and the results, which show a very rapid change, are, if not perhaps unusual for our climate, certainly somewhat striking.

The tests were made with dew point instruments, and I append the figures deduced from my determinations on four days.

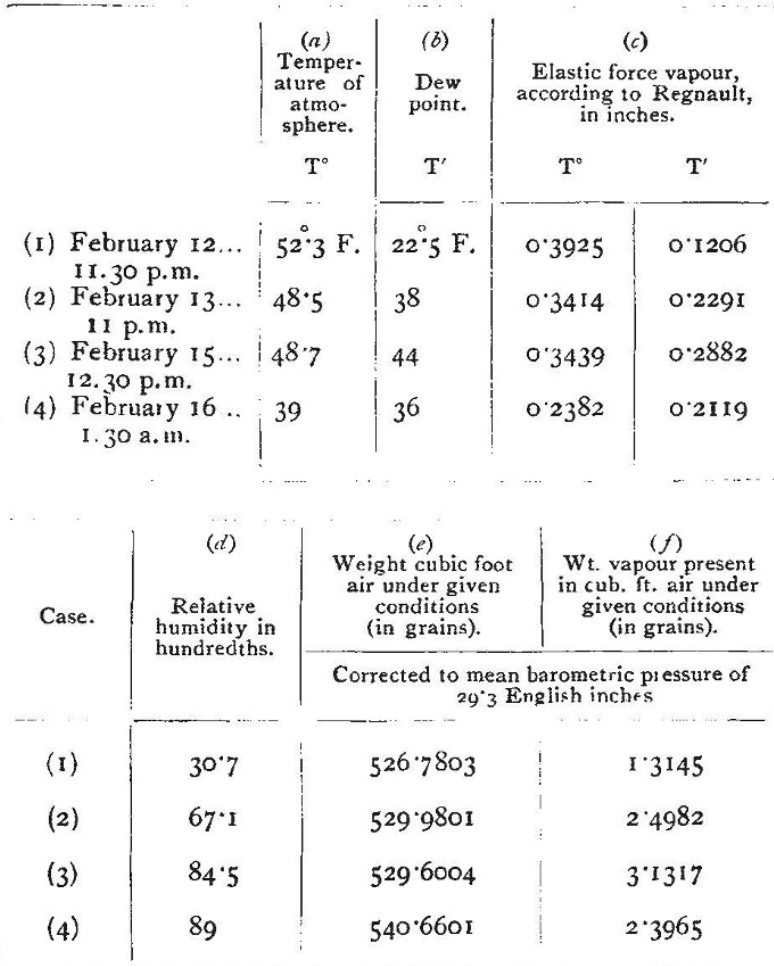

The figures in the last two columns are deduced from the Greenwich observations, while for those in columns $(c)$ and (d) I am indebted to Regnault.

Unfortunately, I have not the height of the barometer at the time of my determinations, but have assumed a mean pressure, covering the four days on which they were made, equal to $29^{\circ} 3$ inches of mercury, and have corrected the figures given in columns $(e)$ and $(f)$ in accordance with this assumption.

The figures given are open to further correction, while some are but approximations.

In case (3), if the relative humidity be calculated by multiplying the factor $100 / \mathrm{F}$ into the elastic force of vapour at the dew point the result, $0^{\circ} 2882 \times 100 / F=290^{\circ} 8=83.8$, is 